\title{
Nem nobre, nem mecânico \\ A trajetória social de um cirurgião na América portuguesa do século XVIII.
}

Neither Noble, nor Laborer: the

Social Path of a Surgeon in $18^{\text {th }}$

Century Portuguese America.

Márcia Moisés Ribeiro

Pesquisadora do IEB-USP

Programa Jovem Doutor - Fapesp

\section{Resumo}

0 artigo tem a finalidade de reconstruir a trajetória social do cirurgião português José Antonio Mendes que permanecera na América portuguesa cerca de 35 anos durante o século XVIII. Dadas as maiores possibilidades de ascensão social oferecidas pela colônia, o cirurgião ocupou cargos de prestígio que dificilmente conseguiria alcançar no reino.

Abstract

This article aims at a reconstruction of the biography of the Portuguese surgeon José Antonio Mendes, who lived in Portuguese America for circa de 35 years in the $18^{\text {th }}$ century. Due to the better opportunities of social ascencion in the Colony, the surgeon reached positions of prestige, probably inaccessible to him in the Court.

Palavras-chave

mineração, Minas Gerais, Portugal, Colônia, Antigo Regime.

Keywords

mining, Minas Gerais, Portugal, Colony, Ancien Régime. 
Supliquemos pois com David ao Todo Poderoso para que nos conceda o precioso dom da sciencia, e por meio della

teremos a dita de passar de humildes á classe de poderosos,

de pobres, ao estado de ricos, de plebeos

a Nobres, e de vassalos inúteis a ser membros

prestadios ao Estado. 1

Luiz da Silva Pereira Oliveira. Privilégios da nobreza e fidalguia de Portugal Lisboa: Oficina de João Rodrigues Neves, 1806, p.68.
Ao enaltecer as ciências e seus cultores no livro Privilégios da nobreza e fidalguia de Portugal, seu autor Luiz da Silva Pereira Oliveira, fez uma ressalva: "nem toda sciencia nobilita", observou alegando que havia diferenças entre os ramos das ciências e que nem todas tinham o mesmo grau de importância. Entre as ciências consideradas nobres estavam a teologia, o direito canônico e civil, a filosofia, a matemática e a medicina. Estas, segundo opinião do autor do tratado, eram extremamente úteis e necessárias para conservação e aumento da República. Mas entre elas, destacava-se uma: a medicina, que segundo Oliveira era a mais nobre das ciências, justamente por ser ela capaz de restituir a saúde dos povos e salvar vidas. Tal juízo, ressalte-se aqui, não era unissono, havendo quem discordasse daquela opinião. Diferentemente de Oliveira, muitos indivíduos não consideravam a medicina um oficio nobre, principalmente porque durante o curso os estudantes precisavam se submeter ao aprendizado de artes mecânicas.

Tão insignes quanto os médicos eram os cirurgiões, escreveu Luiz Pereira Oliveira. Valendo-se da autoridade imposta pelos estatutos da Universidade de Coimbra, segundo os quais se determinava que "a cirurgia estudada, e praticada em todas as suas operações por princípios científico, fosse considerada na mesma graduação e nobreza em que até agora se teve a medicina interna," o autor do tratado argumentava que disputas entre uma e outra categoria só geravam prejuízos ao bem público. E aqui ele se referia ao período anterior à reforma universitária e ás velhas disputas existentes entre os praticantes da medicina e da cirurgia. Nos tempos antecedentes às reformas da Universidade de Coimbra, os cirurgiões gozavam de um estatuto social inferior ao dos médicos. Diferentemente destes, cujo aprendizado girava em torno dos clássicos da Antigüidade como Aristóteles, Hipócrates, Galeno e seus comentadores árabes, os cirurgiões aprendiam seus ofícios sobretudo através da prática.

Oliveira desprezou as velhas distinções sociais que se faziam entre uma e outra profissão alegando que, ao menos teoricamente, tanto o médico como o cirurgião poderiam prestar serviços relevantes e dignos de Ihes conferir nobreza. Embora sugerindo uma igualdade entre as profissões, o tratadista observou que não se podiam confundir os verdadeiros cirurgiões com os simples "cirurgiões flebotômicos", ou seja, com aqueles cuja função principal era a prática das sangrias.

A situação de inferioridade dos cirurgiões em relação aos médicos aparece com clareza em tratadistas mais antigos. Diferentemente dos médicos, cuja nobreza do ofício era reconhecida por todos, os cirurgiões ocupavam uma posição social subalterna. Porém, apesar de praticarem ofícios manuais, não eram considerados mecânicos, situando-se antes em uma camada intermediária.

Inspirando-se certamente na obra de Antônio Vilas Boas e Sampaio, Raphael Bluteau, no seu Vocabulário Português e Latino definiu muito 
Maria Beatriz Nizza da Silva. Ser nobre na colônia São Paulo: Editora da Unesp, 2005 p.p.212,213. Raphael Bluteau, Vocabulário português e latino. Coimbra: Real Colégio das Artes da Companhia de Jesus, 1713. Verbete estado do meio. bem esta situação. ${ }^{2}$ No verbete Estado do meio, aparece a seguinte explicação: "Entre os mecânicos e nobres há uma classe de gente que não pode chamar-se verdadeiramente nobre, por não haver nela a nobreza politica ou civil, nem a hereditária, nem podem chamar-se rigorosamente mecânicos por se diferenciar dos que o são, ou pelo trato da pessoa, andando a cavalo e servindo-se com criados na forma da ordenação... ou pelo privilégio e estimação da arte, como são os pintores, cirurgiões e boticários que por muitas sentenças dos senados foram em vários tempos escusos de pagar jugadas e outros encargos a que os mecânicos estão sujeitos. Era portanto, neste patamar intermediário, situado entre os nobres e mecânicos que se encontravam os cirurgiões, segundo o dicionarista.

Apesar da indistinção entre estes últimos e os médicos sugerida por Pereira Oliveira, o fato é que as diferenças existiam e que a América portuguesa foi herdeira desta separação de categorias. Entretanto, conforme buscarei demonstrar neste artigo, o espaço colonial foi marcado por certa flexibilidade no que diz respeito à distinção que no reino era muito arraigada.

Para tratar desta questão procurarei seguir a trajetória social de José Antonio Mendes, um cirurgião nascido em Portugal e que veio para a América na primeira metade do século XVIII onde permanecera por mais de três décadas exercendo a sua profissão.

Conforme será discutido, a precariedade da assistência médica na colônia acabou autorizando indivíduos de reduzida bagagem teórica a tratar de doenças que, na prática só cabia aos médicos. Formalmente, a estes últimos era facultada a cura das chamadas moléstias internas, enquanto aos cirurgiões cabia o exercício de funções mais simples como as sangrias, a cura de ferimentos, a extração de balas, a aplicação de ventosas e sanguessugas, cirurgias de modo geral e enfim uma série de procedimentos dependentes da habilidade manual. Entretanto, a realidade das Minas como de toda a América portuguesa, marcada pela rara presença de médicos fez com que a força da hierarquia sócio-profissional existente no reino não vigorasse aqui com tanta intensidade, tornando tais diferenças mais tênues.

A separação social entre médicos e cirurgiões assentava-se inicialmente na formação que ambos recebiam. Enquanto os médicos freqüentavam a universidade, os cirurgiões limitavam-se ao aprendizado prático, adquirido sobretudo no Hospital Real de Todos os Santos, em Lisboa. 0 Terremoto de 1755 destruiu o hospital que ainda continuou funcionando até 1755, quando Pombal resolveu transferi-lo para outro prédio, então mudando o seu nome para Hospital Real de São José. Terminado o estágio no hospital, os alunos eram submetidos a exames perante a mestres capacitados e, alcançando bons resultados, recebiam "carta de cirurgião aprovado", a qual era passada pelo cirurgião-mor do reino. Tal documento facultava o exercício da profissão tanto na metrópole como nos seus domínios, permitindo também que os cirurgiões exercessem a medicina onde não residissem médicos, situação esta que foi muito corriqueira na América portuguesa do século XVIII.

Os trópicos não apresentavam grandes atrativos a renomados doutores formados em Coimbra e já bem estabilizados no reino, mas quanto aos cirurgiões a situação era muito diferente. Estes, passaram a ver na América possiveis formas de ascensão social e econômica que dificilmente conseguiriam alcançar na metrópole em função da grande concorrência que havia entre eles. Some-se a isto o fato de que em Portugal a forte presença 
Maria Cristina Cortez Wissembach. Gomes Ferreira e os simplices da terra: experiências sociais dos cirurgiões no Brasil colonial. In Júnia Ferreira Furtado (org.) Erário Mineral Belo Horizonte: Fundação João Pinheiro/ FAPEMIG, p. 123
José Antonio Mendes. Governo de mineiros mui necessario aos que vivem distantes de professores, seis, oito, dez e mais legoas, padecendo por esta causa os seus domesticos e escravos queixas, que pela dilaçam dos remédios se fazem incuráveis, e as mais das vezes mortaes. Lisboa: Oficina de Antonio Rodrigues Galhardo, 1770.

5

Arquivo Nacional da Torre do Tombo - Chancelaria de D. João V. Ofícios e mercês, livro 95

6

Idem. da hierarquia existente entre as diferentes categorias de ofícios, acabava impondo certos limites ás atividades dos cirurgiões, o que não acontecia nos domínios coloniais.

Até o final do século XVIII a raridade numérica de médicos na América portuguesa de certa forma obrigou os cirurgiões a desempenhar funções que, ao menos teoricamente, não Ihes competia. Assim, de simples práticos, viram-se na condição de médicos, ora discutindo teorias, ora procurando demonstrar erudição e ainda curando de moléstias internas.

Além das oportunidades de ascensão econômica - lembrando que vários indivíduos que atuaram nestes ramos tornaram-se ricos comerciantes, donos de fazendas, de lavras e de imensos plantéis de escravoseram muitas as chances de elevação do status social, o que em Portugal seria muito mais difícil devido à maior presença numérica desses profissionais bem como em função da intensidade dos conflitos que havia entre eles e os médicos. ${ }^{3}$

Com poucas exceções, parte considerável dos manuais de medicina escritos na época colonial é de autoria de cirurgiões e não de médicos como seria de se esperar, o que atesta a grande respeitabilidade e prestígio por eles alcançado.

José Antônio Mendes foi um desses profissionais cujo raio de ação foi muito mais amplo do que teoricamente cabia a um cirurgião. Natural de São Vicente do Chão, Arcebispado de Braga, mudou-se para América atuando durante trinta e cinco anos entre as capitanias da Bahia e Minas. Não se sabe a data exata da sua chegada nas terras brasílicas, mas é certo que ele fora um dentre as imensas levas de portugueses que vieram nas primeiras décadas do século XVIII atraidos pelas atividades mineratórias. A fama da obtenção de riqueza fácil, bem como a falta de médicos e cirurgiões em toda a América portuguesa e enfaticamente na região das Minas, devido às altas concentrações populacionais, acabaram por estimulá-lo a permanecer naquela capitania por mais de trinta anos.

Para acompanharmos sua trajetória naquelas paragens existem duas fontes essenciais. Uma delas é o manual de medicina popular que ele escrevera sob o título de Governo de mineiros mui necessário para os que vivem distantes de professores seis, oito, dez, e mais léguas, padecendo por esta causa os seus domésticos e escravos queixas, que pela dilação dos remédios se fazem incuráveis, e a mais das vezes mortais. ${ }^{4} 0$ livro foi publicado em Lisboa no ano de 1770.

Outra importante fonte de informações sobre a sua vida encontra-se nos livros da Chancelaria de D. João V. 5 Segundo consta no documento, José Antônio Mendes teve sua formação prática em Lisboa no Hospital Real de todos os Santos, onde então conseguira carta de cirurgia no ano de 1739, certamente poucos anos antes de sua chegada na América.

Obtendo aprovação e "carta de cirurgia" partiu para a América onde residiu por vários anos, primeiramente na Bahia e depois nas Minas. Foi nesta capitania que ele passara boa parte de sua vida, trabalhando nos hospitais do Contrato diamantino e no hospital do Regimento dos Dragões da capitania das Minas, também localizado no Serro do Frio.

A respeito da trajetória profissional de José Antonio Mendes existe um fato bastante significativo. Conforme consta nos livros da Chancelaria de D. João $V$, ele não aprendera anatomia durante os dois anos estivera no Hospital Real de Todos os Santos, e a razão disto foi a inexistência do curso durante aquele periodo. ${ }^{6}$ À época a anatomia era tema bastante contro- 
Lycurgo Santos Filho. História geral da medicina brasileira São Paulo: Edusp/Hucitec, 1991, p.268.

Governo de mineiros...p. XV verso. Em 1704 foi criada uma cadeira destinada exclusivamente ao seu ensino, porém, devido a uma série de impedimentos ligados a princípios religiosos, ela logo foi extinta. Além do mais, durante o breve período de existência da cadeira naquele hospital, a anatomia voltava-se muito mais à teoria do que à prática. Examinado pelo cirurgião-mor do reino Francisco Xavier Leitão, José Antonio Mendes foi aprovado por se verificar que ele era muito aplicado nos estudos. Mesmo não tendo aprendido anatomia, Mendes conseguira a carta de "cirurgião anatômico" aprovado, título que mais tarde iria ajudá-lo a alcançar o elevado posto de comissário geral do cirurgiãomor do reino em toda a América.

A fiscalização dos profissionais da saúde nos domínios coloniais cabia a duas grandes autoridades: ao comissário do físico-mor e ao cirurgião-mor do reino. Eram eles os responsáveis pelo exame dos candidatos à profissão de cirurgião-barbeiro, barbeiro, sangrador, parteira, aprendiz ou oficial de boticário. Feitos os exames, mandavam-se os resultados para Portugal, onde se concediam ou não as licenças solicitadas. Ao comissário do cirurgiãomor cabia também a inspeção das boticas de três em três anos, as vistorias dos hospitais, a verificação do estado de conservação e preços de medicamentos, além de medidas referentes à defesa sanitária na colônia. ${ }^{7}$ Tratavase assim de um cargo de grande responsabilidade, que demandava bastante habilidade profissional e que acabava conferindo muito prestígio e distinção a quem o ocupava.

A questão da diferenças entre os domínios da medicina e da cirurgia perpassa todo o Governo de mineiros, e logo no início seu autor faz diversas justificativas no intuito de explicar as razões que o levaram a adentrar em uma seara que, ao menos teoricamente, não era sua. 0 livro trata longamente de assuntos próprios ao território dos médicos, como a indicação de remédios para moléstias internas, trazendo ainda discussões sobre as suas causas. 0 principal motivo que o levara a escrever um guia foi a falta de socorro médico a que estavam sujeitos constantemente os escravos na capitania das Minas. Assim o cirurgião se sentia na obrigação de falar a respeito não só das quantidades dos remédios mas também das suas qualidades e manipulação, o que, ao menos teoricamente, não era sua função, pois dessa forma possibilitava aos "... curiosos da dispersa América, mais livres do susto, remediar seus escravos e domésticos de suas casas. Estas as razões que me obrigam a falar nesta obra em vários remédios internos, que nada tocam as margens da Arte Cirúrgica..." 8

$\mathrm{Na}$ América portuguesa a erudição e bagagem teórica dos profissionais da medicina tinham peso muito menor do que na metrópole. Frente a realidade tão distinta da do Velho Mundo, mais valia a prática, própria ao ofício dos cirurgiões do que o domínio profundo de conceitos e teorias. 0 clima diferente e as doenças, muitas vezes desconhecidas dos europeus, acabaram deixando as velhas lições aprendidas na Universidade de Coimbra em segundo plano.

No prólogo ao leitor, Mendes deixou claro que seu guia destinavase aos pobres e sem recursos para contratar os serviços dos cirurgiões, e sobretudo aos senhores de escravos que viviam distantes de médicos e portanto precisavam de um guia prático para as necessidades do dia a dia. Atento á situação em que viviam as populações nas Minas, escreveu o seguinte "...Vós bem vedes que ainda neste reino há lugares tão limitados, e pobres, que neles não há médicos, nem ainda cirurgiões, e só sim um simples barbeiro que intrépida e atrevidamente se mete a curar ainda a mais execranda maligna que se the oferece" 9 
10

Ibidem

11

Idem, p.30.

12

Luis Gomes Ferreira. Erário Mineral, dividido em doze tratados Lisboa: Oficina de Miguel Rodrigues, 1735.

13

Ver o prólogo ao leitor.
Durante todo o século XVIII e até meados do XIX foi muito intensa a luta da medicina institucionalizada contra as práticas exercidas informalmente por curandeiros. Frente a isto, mesmo não possuindo grande erudição, os cirurgiões passaram a ser mais valorizados não apenas pelas autoridades responsáveis pela saúde, como também pelas parcelas mais esclarecidas da população colonial. Cada vez mais conscientes da importância de seus ofícios, alguns entre os cirurgiões que viveram na América portuguesa escreveram guias práticos de medicina, visando com isto alcançar maior popularidade e promoção sócio-e econômica. Escritos normalmente em linguagem clara e acessível, este gênero de livro foi muito bem aceito pelas autoridades metropolitanas.

Mesmo sabendo que a indicação de remédios era própria aos médicos, José Antonio Mendes costumava receitá-los e para tanto usava justificativas bastante cabiveis na realidade em que vivia: "Já conheço que me responderão que a administração dos remédios internos pertence aos professores de medicina, e que estes como heróis de tanta ciência terão por inúteis as minhas advertências. Confesso que sim; porém como eu só faço esta obra para curiosos, que vivem apartados de todo o uso e aplicação dos remédios, e só os usam nas suas necessidades aos seus domésticos, e escravos, e como naquelas paragens não há professores, se faz preciso que os mesmos curiosos saibam o modo como hão de administrar os remédios anteriormente por suas quantidades e qualidades. ${ }^{10}$ Num tom de modéstia que não correspondia necessariamente à realidade, o cirurgião justificava o "estilo grosseiro"do guia, entretanto, alegava que ele não fora feito "para os limados, e só para aqueles que talvez nem ler saibam, e que Ihes seja preciso mandar ler este livrinho..." 11

José Antonio Mendes não fora o único cirurgião da capitania das Minas a escrever sobre assuntos que fugiam ao seu domínio. Também nas Minas da primeira metade do século XVIII vivera o cirurgião português Luis Gomes Ferreira, autor do mais significativo livro de medicina prática que se escreveu sobre a América portuguesa. Trata-se do Erário mineral, publicado em Lisboa em 1735.12De dimensões mais ampla que o livrinho de Mendes, o trabalho de Ferreira tratou sobejamente de assuntos pertencentes á medicina. Buscando defender-se de possiveis censuras, fez a seguinte observação: "se for censurado por escrever de medicina sendo professor de cirurgia, respondo que a cirurgia é parte inseparável da medicina, e demais, que, nas necessidades da saúde, os cirurgiões suprem em falta dos senhores médicos..."13Seus argumentos foram mais que convincentes e prova disto é fato de seu livro ter sido publicado em Lisboa com todas as licenças necessárias. Além do mais, é preciso ressaltar que se tanto o autor do Erário Mineral como do Governo de mineiros - além de outros cirurgiões e autores de manuais de medicina prática- se atreveram a falar publicamente sobre temas que teoricamente não Ihes cabia é porque, na realidade, contavam com o apoio do governo metropolitano.

0 governo de mineiros está dividido em 15 capitulos, estando cada um deles voltado para a descrição de um tipo específico de doença e de sua respectiva cura. A linguagem utilizada é simples e direta, refletindo a clara intenção do seu autor de ser útil às populações pobres e carentes de médicos. Além de tratar de assuntos a respeito de males que com freqüência requeriam a intervenção dos cirurgiões, o livro também é riquíssimo em informações sobre o dia a dia da região da capitania das Minas, abordando grande variedade de temas como a violência cotidiana, o trabalho e 
a alimentação dos escravos e as condições do transporte maritimo entre a costa africana e o Brasil, etc. Afora os capitulos mais convencionais relativos á arte da cirúrgica, existem outros dedicados a discussões pertencentes à medicina. Foi justamente nesses capítulos atinentes à medicina que o autor relatou com mais minúcia o dia a dia dos colonos envolvidos com os trabalhos de extração do ouro, especialmente os escravos.

Assim como Luis Gomes Ferreira, Mendes descreveu as causas, os sintomas e os métodos curativos das doenças mais freqüentes na capitania das Minas. Seu grande alvo foi a abordagem de assuntos relativos às causas e tratamento de males mais comuns entre os escravos, o que por sua vez atendia de maneira intensa aos interesses da coroa na preservação de sua força de trabalho. No livro, o enfoque de tais questões aparece diretamente relacionada o universo do trabalho, enfaticamente à extração do ouro e das condições materiais às quais os escravos eram submetidos cotidianamente.

Os trabalhos da mineração expunha os escravos a freqüentes contatos com a friagem e a umidade, razão pela qual José Antônio Mendes dedicou várias páginas de seu guia a comentários acerca das doenças pulmonares. Para tais problemas, o tratamento indicado combinava tradicionais práticas da arte médica européia, com o uso de remédios formulados com produtos da farmacopéia local .

Os princípios da medicina ibérica e suas freqüentes indicações de sangrias estão muito presentes no Governo de Mineiros. Igualmente de raiz européia são muitos medicamentos receitados pelo cirurgião, porém a maior parte deles pertencia à farmacopéia indígena.

Mesmo saindo de hospitais de Lisboa, cirurgiões que vinham para a América como foi o caso de José Antonio Mendes acabavam se rendendo aos métodos curativos locais já que grande parte das vezes não havia outra alternativa. Além da dificuldade de obtenção de medicamentos da Europa havia ainda problemas advindos de seu transporte no interior da própria colônia e ainda os impedimentos resultantes do alto preço pelos quais normalmente eram vendidos. Perante a tais circunstâncias, conhecimentos da medicina tradicional da Europa foram forçosamente mesclados ás experiências advindas de africanos e indígenas. Assim, diferentemente da postura dos raros doutores de Coimbra que dispuseram-se a atravessar o atlântico para exercer seus ofícios nas terras tropicais, cirurgiões, barbeiros e sangradores, alargaram seu receituário baseando-se no aprendizado que tinham no dia a dia com as populações locais.

Além das doenças respiratórias, muito freqüentes nos negros que trabalhavam na exploração do ouro, havia ainda grande incidência de hemorragias intestinais, mais conhecidas na época por cursos de sangue. José Antonio Mendes contou aos leitores que na época de sua permanência no hospital do Contrato Diamantino, costumava atender cerca de 500 pessoas por ano com queixas de problemas hemorrágicos. Deixando de lado este dado numérico, o fato é que se tratava de uma enfermidade muito comum na região.

Sendo sua clientela composta majoritariamente por negros, ele atribuia os surtos hemorrágicos principalmente à má alimentação dos escravos e ao consumo de água misturada com terra ou ferrugem. Sobre isto observou, "...fazem a noite os ditos negros uma massa a que chamam angu, que é feita de fubá, isto é de farinha de milho, muito mal feita no moinho, e feita a dita massa em água sem sal, nem mais tempero algum e ás vezes bem mal cozida, esta fica feita a noite com algum resto de feijão 


\section{4}

Governo de mineiros... p.69.

15

Idem, idem.

16

Idem, p.45

17

Idem, p.29, p.53.

18

Márcia Moisés Ribeiro. A Ciência dos trópicos - a arte médica no Brasil do século XVIII São Paulo: Hucitec, 1997.

19

Além do tratado sobre o escorbuto, João Cardoso de Miranda dedicou-se a outros trabaIhos sobre as doenças na América portuguesa. que sobejou da ceia, e assim, tudo frio é o almoço de que atualmente usam - o jantar é sempre um pouco de milho cozido em um tacho de cobre, a que não falta zinabre e quase sempre mal cozido; este é o jantar e sem mais nada, quanto a ceia é um pouco de feijão preto com uma limitada porção de sal e sem mais algum tempero, este costuma ir acompanhado com o celebrado angu..$^{14}$ Não bastando alimentação tão pesada prejudicial á saúde somava-se ainda o consumo de água suja normalmente retirada dos próprios locais onde se extraia o ouro. 0 abuso da cachaça pelos negros também era apontado pelo cirurgião como causador das hemorragias. ${ }^{15}$

0 hábito de trabalharem descalços expunha os escravos a constantes perigos. De acordo com relatos do cirurgião, instrumentos perfurantes como pregos, vidros ou "outra qualquer coisa capaz de entrar na sola ou planta do pé" foram agentes causadores de muitas mortes nas Minas. ${ }^{16}$ A grande preocupação do autor era alertar aos senhores sobre a importância da rapidez do socorro em caso de acidentes, razão pela qual Mendes recomendava aos senhores que tivessem em suas lavras ou roças tesouras, agulhas, e outros instrumentos cirúrgicos como tentas e mais remédios necessários "...porque o (seu) custo é bagatela e suponde que pelo não teres prontos, vos morre um escravo,e ainda que não suceda senão de dez em dez anos, perdeis mais do que vos custam esse símplices e compostos que vos digo, e desencarregais a vossa consciência em acudires ao vosso escravo, e neste caso também o vosso próximo que é o que mais agrada a Deus." ${ }^{17}$ Adequando os princípios da humanidade cristã ao consentimento da escravidão, os senhores deviam dar o sustento aos escravos o que subentendia a alimentação, o vestuário e o cuidado nas enfermidades, garantindo assim a continuidade da exploração colonial. ${ }^{18}$

Outro capítulo dedicado quase com exclusividade a males freqüentes entre as populações escravas é o que trata do mal de Luanda ou escorbuto. 0 cirurgião parece apresentar certo constrangimento ao discorrer sobre aquela enfermidade e isto porque na década de 50 do século XVIII João Cardoso de Miranda, outro cirurgião muito conceituado nas terras coloniais, dedicara um estudo à cura do escorbuto. Trata-se da Relação cirúrgica e médica na qual se trata e declara especialmente um novo método para tratar a infecção escorbútica, ou mal de Luanda, e todos os seus produtos, fazendo para isto manifesto dois específicos e mui particulares remédios", livro que gerou muita discussão entre médicos e cirurgiões no portugueses. 19

Disseminado em toda a América, o mal de Luanda não cessava de fazer novas vítimas, fato que levara o cirurgião das Minas a atribuir o aumento da doença á falta de preparo dos professores de medicina. Ainda que de forma discreta, ele punha em questão os conhecimentos daqueles indivíduos, ao passo que enaltecia os seus próprios méritos. E aqui transparece claramente a sua opinião: mais valia a experiência prática dos cirurgiões que atuavam lado a lado com os colonos e seus conhecimentos sobre as doenças e as curas do que os saberes teóricos dos doutores coimbrãos.

Semelhante ao que ocorria em relação às hemorragias, na opinião de Mendes as causas do escorbuto entre os escravos também estavam ligadas à ingestão de alimentos em mau estado de conservação, os quais eram muito comuns durante travessia maritima. Ele não aludiu à falta de vitamina $\mathrm{C}$ ou ao baixo consumo de vegetais frescos, atribuindo suas causas à ingestão de alimentos corruptos e à água contaminada transportada nos tumbeiros. Embora não tivesse uma noção mais exata do que fosse 0 
20

Governo de mineiros...p.86

21

Idem, p.93

22

Sérgio Milliet, curandeiros,médicos e farmacêuticos no Brasil colônia / separata da Revista Investigações. Ano II- São Paulo, março de 1950, n.15

23

Arquivo Público Mineiro - Seção colonial,Cód.02

24

Governo de mineiros...p.93 escorbuto, o capítulo destinado à sua descrição é muito rico em informações sobre as condições das viagens entre a África e a América portuguesa, revelando dados significativos sobre alimentação, e outros detalhes sobre 0 transporte negreiro.

Nem só no mar se contraía o tão temido mal de Luanda, acrescentou José Antônio Mendes. As condições próprias aos trabalhos da extração do ouro também favoreciam o aparecimento da doença, explicou. "Estas mesmas causas de que procede aos que vem embarcados esta queixa, podem atribuir-se aos que labutam nos serviços de minerar, e nos que andam no contrato dos diamantes, pois andam metidos continuamente na água bebendo muitas vezes das mesmas águas cheias de lodo, e outras imundicies, deitam-se ao sol quando o há forte que os frige, outras vezes deitam-se molhados, havendo frios intoleráveis, e todo este desordenado regime é causa desta impertinente queixa..." 20 .

Além de recomendar ervas e raízes, o cirurgião português indicava um medicamento preparado especificamente contra aquela enfermidade. Entretanto, observou que seria mais prudente adquiri-lo fora da capitania das Minas, pois aí a falsificação do antiescorbútico era prática freqüente.21 No próprio arraial do Tejuco havia quem o manipulasse com honestidade, porém isto só acontecia em uma botica, observou o cirurgião. Provavelmente era ele mesmo quem preparava o remédio ou algum boticário de crédito.

0 problema da adulteração de medicamentos foi muito freqüente na América portuguesa. Movidos pela falta dos produtos componentes das fórmulas originais, pelos seus altos custos e ainda pela ma fé, muitos droguistas alteravam as receitas originais, o que por sua vez causava constantes conflitos entre as populações e os responsáveis pelo controle da área da saúde. Os problemas não ficavam limitados ao enfrentamento entre as autoridades e as populações de forma geral, gerando conflitos entre os próprios boticários e vendedores de drogas. Tentando preservar seus próprios negócios, muitos fabricantes de remédios levantavam suspeitas sobre a qualidade dos produtos preparados por seus concorrentes, lembrando que aquele comércio sempre fora atrativo e capaz de gerar de disputas pelo seu monopólio. ${ }^{22}$

A manipulação e a venda de remédios sem licença das autoridades competentes era alvo de constantes perseguições por parte dos representantes do cirurgião-mor na colônia, entretanto isto só acontecia nas vilas e cidades mais populosas e onde a existência da medicina institucionalizada era mais perceptível; do contrário predominava a falta de critérios e os abusos dos comerciantes. Em meados do século XVIII, quando a presença dos representantes de Lisboa em matéria de saúde tornou-se mais freqüente nas terras coloniais foram tomadas várias medidas em relação ao assunto. 0 droguista que fosse autuado pela falsificação de remédios, além de penas pecuniárias podia ter seu estabelecimento fechado. ${ }^{23}$

Além da botica situada no Contrato Diamantino José Antonio Mendes recomendava aos leitores que comprassem o remédio antiescorbútico nas lojas de drogas da Bahia ou do Rio da Janeiro, onde então residia o licenciado Miguel Rodrigues de Batalha, considerado por ele um insigne farmacêutico ${ }^{24} \mathrm{~A}$ indicação de boticas mais longínquas, além de uma localizada no Contrato, seria portanto uma forma de preservar seus próprios interesses ou de alguém de sua confiança. Em função da longa distancia existente entre Minas e Bahia e também do Rio de Janeiro, e ainda diante da aspereza dos 
25

Luiz da Silva Pereira Oliveira, op.cit., p.207; sobre a situação dos boticários luso-brasileiros na sociedade setecentista é essencial ver o trabalho de Vera Regina Beltrão Marques, Natureza em boiões- medicinas e boticários no Brasil setecentista, principalmente o capítulo 3 .

26

Luiz da Silva Pereira Oliveira, op cit., p.207

27

Idem, p.208

28

Vera Regina Marques Beltrão, op.cit. , p.175

29

idem, idem. caminhos e da dificuldade do transporte de mercadorias, tais produtos deveriam chegar ao seu destino a preços bem elevados, o que certamente desestimulava as populações da região do Contrato a consumi-los.

Através da leitura do Governo de mineiros fica evidente que José Antonio Mendes não apenas tinha conhecimento da arte da manipulação de remédios, como também costumava, mesmo que eventualmente, cuidar de seu preparo. Entretanto, é importante ressaltar que se tratava de uma prática incompativel com o ofício dos cirurgiões.

Teoricamente, a preparação de mezinhas cabia ao boticário e não ao médico ou ao cirurgião. Na definição de Raphel Bluteau, além de vendedores de drogas os boticários eram uma espécie de "cozinheiros dos médicos" ,ou seja, indivíduos cuja função era livrar os mesmos do trabalho mecânico, tratando-se assim de uma função manual e portanto desqualificadora. 25

Segundo Luiz da silva Pereira Oliveira, o autor de Privilégios da nobreza e fidalguia de Portugal, citado no início deste artigo, em Portugal de tempos mais remotos, os boticários não foram dignos de qualquer nobreza, porém, na tentativa de incentivá-los, D.Afonso $V$ concedeuIhes as mesmas honras e privilégios de que gozavam os físicos e cavaleiros. 0 oficio passara a ser tão atrativo que o número de boticários aumentara intensamente, razão pela qual em pouco tempo a profissão foi perdendo seu prestígio. Segundo o tratadista, "El Rey D. Affonso V, para os animar a seguir esta útil profissão em benefício do Estado, que deles estava falto concedeu-Ihes todas as honras e privilégios de que então gozavam os físicos, e os cavaleiros e ordenou, que nos pleitos se lhes contassem custas como a nobres; facultou-Ihes poderem usar d'Armas e de Sedas, concedendo-Ihes homenagens, aposentadoria e isenção de todos os encargos, para o que Ihes passou carta de Lei em 22 de abril de 1449. Correndo o tempo foram tantos e tais os que se aplicaram a esta arte farmacêutica, que a fizeram cair de estimação, de sorte que quando o Senhor rei D. Sebastião deu regimento ao Mordomo Mor em 3 de janeiro de 1572 e quando o Senhor D. Filipe promulgou as ordenações do Reino em 1603, já os boticários nestas legislações foram nomeados misturados e confundidos com outros oficiais mecânicos"26 0s próprios estatutos da Universidade de Coimbra definiam a manipulação de mezinhas como arte mecânica e subalterna à medicina. Contudo, ressaltava Pereira Oliveira, mesmo se tratando de arte "inferior" os estudantes de medicina não deveriam desprezá-la, pois ela não infundia " mecânica em quem a não exercita de modo servil, mas só para adquirir os conhecimentos necessários para praticar com acerto a mesma medicina"27

Conforme procuramos demonstrar ao longo deste artigo, a América portuguesa herdou várias distinções de categorias profissionais existentes no reino, entretanto a realidade colonial foi bem mais flexível. Não apenas na capitania das Minas, mas em todo a extensão da colônia portuguesa da América, foi muito freqüente a atuação de cirurgiões tanto na área da medicina como no domínio dos boticários. ${ }^{28}$ Em Pernambuco do século XVII, o médico Simão Pinheiro Morão, acusava os cirurgiões de manipularem remédios sem ter o menor conhecimento a respeito de suas virtudes. ${ }^{29} \mathrm{Em}$ Minas o já referido cirurgião Luiz Gomes Ferreira também preparava uma série de medicamentos, o que era incompativel com a sua formação.

Depois de pedir desculpas aos leitores, José Antônio Mendes fez diversos comentários a respeito de medicamentos que ele próprio inventara. 
30

Júnia Ferreira Furtado. Arte e segredo: o licenciado Luis Gomes Ferreira e seu caleidoscópio de imagens, in Júnia Ferreira Furtado(org.) op. cit., p.17.

31

Governo de mineiros....p.98

32

Idem, p.133

33

Maria Beatriz Nizza da Silva. Vida privada e quotidiano no Brasil Lisboa: Editorial Estampa, 1993, p. 323.
Além de descrever fórmulas de mezinhas, o cirurgião ensinava detalhadamente como prepará-las, fornecendo informações minuciosas a respeitos dos recipientes ideais para cozimento dos ingredientes, consistência dos mesmos, modo correto de mexê-los e ainda outros pormenores próprios a quem estava acostumado com o exercício daquelas tarefas. Ao fazer papel de boticário, Mendes reconhecia estar transgredindo as normas, porém justificava seus atos alegando que tudo era feito em nome de uma causa mais ampla: socorrer aos pobres e senhores de escravos que viviam apartados de médicos, cirurgiões e boticas, o que não foi incomum até a vinda da Corte para o Brasil.

Assim como ocorrera no caso de outros livros do mesmo gênero, no Governo de mineiros é manifesta a necessidade do seu autor de tornar publico os casos de cura bem sucedidos durante os longos anos em que ele permanecera na América ${ }^{30}$.

Tratando-se de uma sociedade de Antigo Regime onde os valores pessoais eram medidos em função das imagens públicas, para conquistar maior clientela e respeito das pessoas os cirurgiões procuravam divulgar ao máximo as suas habilidades e sucessos alcançados. Contra chagas comuns aos portadores do mal de Luanda Mendes divulgou a existência de um remédio poderosíssimo, declarando serem tantas as curas obtidas, que se ele fosse declará-las uma a uma, seria necessário escrever um livro de grande volume ${ }^{31} .0$ produto indicado era a manteiga de antimônio. Enaltecendo os seus próprios méritos, constatou que os professores de cirurgia não tinham conhecimentos comparáveis aos seus a respeito daquele remédio, pois do contrário deveriam venerá-lo, assim como ele fazia. Muitos foram também os casos de curas dificeis que conseguira quando tratou de algumas pessoas enviadas ao hospital do Contrato Diamantino pelo contratador João Fernandes de Oliveira32. Já de volta a Portugal e provavelmente pouco tempo antes da publicação do livro, Mendes continuara exercendo sua arte onde também disse ter alcançado muito sucesso curando pessoas bem situadas na sociedade. Ao nomear indivíduos respeitados socialmente e relatar casos dificeis em que obtivera bons resultados, acabara exercendo de forma intensa a sua auto publicidade. Foi esta sem dúvida a maneira que encontrou para se destacar dos seus concorrentes.

Além de trabalhar no hospital do Contrato dos Diamantes, Mendes era cirurgião do hospital dos dragões da guarnição de Minas Gerais, um hospital militar também situado na comarca do Serro do Frio.

A expressão mais nítida da preocupação da coroa portuguesa em relação á saúde de seus vassalos deu-se sobretudo a partir do século XVIII quando então foram criados hospitais militares em diversos lugares da América portuguesa. A eles cabia prestar assistência aos soldados feridos e enfermos e, ao contrário das misericórdias, não recebiam esmolas particulares, valendo-se apenas das contribuições estatais 33 . Contando com poucos recursos governamentais que thes eram destinados, esses hospitais foram marcados por quadros de extrema miséria. Ilustra muito bem situação daquelas instituições militares, os relatos sobre o mau estado do hospital militar de Santos enviados ao Morgado de Mateus no tempo em que ele estivera á frente do governo da capitania de São Paulo. Após comunicar a morte de alguns soldados, o responsável pela sua administração alegara que as doenças e a causa daquelas mortes deviam-se ás péssimas condições hospitalares, " pois estando lá 23 doentes, se acham 12 cobertores muito incapazes, e lençóis só para 12 camas que ainda que seja preciso 
34

Biblioteca Nacional Arquivos de Mateus. I$30,19,9$ n.2 muda-los não há outros e quando se vão lavar ficam os doentes sem eles e outras mais faltas que privam tratarem-se os doentes como pede a humana caridade"34. A situação do hospital militar onde Mendes trabalhava não devia ser muito diferente, lembrando que de maneira geral, que até o fim do século a assistência hospitalar na América portuguesa foi marcada pelo signo da carência e da pobreza. Mesmo não havendo nenhum capítulo de seu livro dedicado com exclusividade á sua experiência como cirurgião do Hospital dos Dragões, nas páginas onde descreve as feridas, mencionou vários casos de ferimentos feitos com instrumentos perfurantes como os estoques, ou seja, um tipo de espada normalmente usadas por soldados.

Percorrendo a trajetória seguida por José Antonio Mendes, nota-se que eram muitas as suas ocupações. De simples cirurgião, como tantos que saiam ano a ano do Hospital Real de Todos os Santos, e que nem possuía formação na área de anatomia, viera para a América portuguesa onde exerceu várias atividades relacionadas à sua profissão. E sobre esta diversidade de funções existe um ponto muito significativo. Conforme foi comentado, além de cirurgião, José Antonio Mendes ora se fazia de médico receitando remédio para moléstias internas, ora de boticário, manipulando mezinhas e "cozinhando para os médicos", conforme as palavras de Bluteau há pouco referidas, entretanto, esses fatos interferiram positivamente no seu processo de ascensão social.

0 que na metrópole poderia desqualificá-lo, como foi o caso de seu envolvimento na manipulação de remédios, na colônia não the trouxe qualquer prejuizo. Ele, como outros cirurgiões da época antecedente aos novos estatutos de Coimbra, nunca pode ser igualado aos médicos, isto é, aos nobres, conforme mais tarde seria sugerido por Luiz da Silva Pereira Oliveira, assim como não se nivelou aos mecânicos, apesar de desempenhar trabalhos de boticário. Prestando serviços relevantes ao Estado, Mendes tornou-se comissário do cirurgião-mor do reino em toda a América.

Com a reforma pombalina da Universidade de Coimbra os cirurgiões passaram a gozar do mesmo estatuto social do médicos, porém a esta altura José Antonio Mendes já havia retornado a Portugal onde ainda continuou exercendo as suas artes. 